\title{
A IMPORTÂNCIA DA ROTINA NA EDUCAÇÃO INFANTIL COMO ALICERCE PARA O TRABALHO DOCENTE DE QUALIDADE.
}

\author{
Indira Aparecida Santana Aragão
}

Universidade Estadual Paulista - UNESP, Presidente Prudente, SP. E-mail: indyra sa12@hotmail.com. Órgão de fomento: Pibic/CNPq.

\section{RESUMO}

Este artigo se constitui como recorte da pesquisa de iniciação científica intitulada Formação Profissional para a docência na Educação Infantil: contribuições a partir da análise de propostas pedagógicas/curriculares praticadas em creches e pré-escola, realizada nos anos de 2011-2013. 0 objetivo se constituiu compreender como as rotinas são planejadas e organizadas. A pesquisa qualitativa se caracterizou como estudo de caso e tinha como método de coleta de dados a analise documental e a observação. Os dados apresentados nos permitem inferir o cumprimento de rotinas padronizadas e rígidas que contam com pouca ou quase nenhuma participação das crianças, bem como constatar a diferenciação entre rotinas da creche e rotinas da pré- escola. Os resultados indicam a necessária reflexão das rotinas como elemento norteador das práticas nas instituições de educação infantil, e que contribuem para o trabalho docente de qualidade, buscando superar práticas que não consideram a criança como centro do processo educativo.

Palavras-chave: Educação Infantil, Rotinas, Proposta Pedagógica.

\section{EDUCATION OF ROUTINE IMPORTANCE AS CHILDREN FOUNDATION FOR WORK QUALITY TEACHERS.}

\begin{abstract}
This article represents the trimming undergraduate research titled Vocational Training for teachers in kindergarten: contributions from the analysis of educational / curriculum proposals practiced in day care and preschool, conducted in the years 2011-2013. The goal was constituted understand how routines are planned and organized. Qualitative research was characterized as a case study and had as data collection method documentary analysis and observation. The data presented allow us to infer the performance of standardized and rigid routines that have little or no participation of children and noting the difference between the nursery routines and routines of pre-school. The results indicate the necessary reflection of the routines as the guiding element of the practices in early childhood institutions, and contribute to the teaching quality, seeking to overcome practices that do not consider the child as the center of the educational process.
\end{abstract}

Keywords: Early Childhood Education, Routines, Pedagogical. 


\section{INTRODUÇÃO}

Este artigo se constitui um recorte da pesquisa de iniciação científica intitulada Formação Profissional para a docência na Educação Infantil contribuições a partir de análise das propostas pedagógicas praticadas em creches e pré-escola e teve como objetivo analisar as propostas pedagógicas / curriculares triênio 2010-2012 (creche e pré-escola) de um município de médio porte do interior do estado de São Paulo, realizada nos anos de 2011-2013 com a intenção de identificar experiências bem sucedidas, fragilidades, deficiências, lacunas, antagonismos na busca de elucidar elementos que sinalizem para qualificação da formação profissional dos docentes da educação infantil e por consequência contribuir para a construção de um currículo que possibilite de fato e de direito um atendimento de qualidade às crianças menores de seis anos de idade.

A pesquisa foi realizada em três etapas: análise das propostas pedagógicas das instituições, aplicação de questionário, observação. Neste artigo apresentaremos alguns dados da análise das propostas pedagógicas e das observações com o objetivo de trazer algumas questões para debate e reflexão no que se referiu à organização das rotinas nas instituições de educação infantil.

Compreendemos que a proposta pedagógica é o plano orientador das ações práticas da instituição, aquele em que se definem as metas e objetivos que ser quer atingir.

A proposta pedagógica, ou projeto pedagógico, é o plano orientador das ações na instituição e define as metas que se pretende para o desenvolvimento dos meninos e meninas que nela são educados e cuidados, as aprendizagens que se quer promovidos. Na sua execução, a instituição de educação infantil organiza seu currículo, que pode ser entendido como as práticas educacionais organizadas em torno do conhecimento e em meio ás relações sociais que se travam nos espaços institucionais, e que afetam a construção das identidades das crianças. (BRASIL, 2009, p.06).

Este artigo tem por finalidade, analisar como se constituiu a organização da rotina nas Propostas Pedagógicas e nas práticas realizadas nas instituições de Educação Infantil da Rede Municipal de Presidente Prudente.

\section{METODOLOGIA}

A pesquisa qualitativa caracterizada como descritiva e analítica, tendo como método de coleta de dados, a análise documental e a observação, visto que pretende registrar os caminhos pelos quais os profissionais se utilizam para a elaboração e implementação das rotinas.

A análise documental consiste em verificar documentos e extrair deles informações de acordo com o objetivo do pesquisador, conforme afirma (BOGDAN; BIKLEN, 1994, p.180) “Nesses 
documentos os investigadores podem ter acesso à "perspectiva oficial", bem como as várias maneiras como o pessoal da escola se comunica."

Enquanto que a observação de acordo com (MAZZOTTI; GEWANDSZNAJDER, 1999, p.164) "A observação permite "checar", na prática, a sinceridade de certas respostas que, às vezes, são dadas só pra "causar boa impressão"."

Desta forma a pesquisa enquadra-se também na modalidade estudo de caso, visto que é o estudo de um caso - as creches e pré-escolas da Rede Municipal de Presidente Prudente, que mesmo sendo similar a outros é ao mesmo tempo diferente, pois tem características que o tornam único (LUDKE; ANDRÉ, 1986).

O universo da investigação é composto pelas escolas municipais de educação infantil, num total de 42 , tendo as seguintes modalidades:

- Creche: 6 Unidades;

- Pré-Escola: 1 Unidade

- Creche e Pré-Escola: 11 Unidades

- Creche, Pré-Escola e Ensino Fundamental: 6 Unidades

- Pré-Escola e Ensino Fundamental: 13 Unidades

- Creches Filantrópicas (Creche E Pré-Escola): 5 Unidades

Para a realização da pesquisa foram selecionadas 6 escolas com autorização da Secretaria de Educação, respeitando o critério de que cada escola representasse uma modalidade de ensino, ficando assim denominadas:

- Creche: EM WM

- Pré-escola: EM JB

- Creche e Pré-escola: EM EMD

- Creche, Pré-escola e Ensino Fundamental: EM OA

- Pré-escola e Ensino Fundamental: EM ERR

- Creches filantrópicas: Creche AFB

Foram realizadas leituras sobre o contexto histórico, no sentido de compreender como o atendimento à criança pequena se originou e foi se constituindo. Os documentos denominados pela Secretaria de Educação do município como "planos diretores ou planos de ensino" trienais de 2010 a 2012, foram analisados em confronto com os documentos oficiais que normatizam e regulamentam a Educação Infantil no Brasil.

Elaboramos categorias de análise com base nas Propostas Pedagógicas e Currículos em Educação Infantil (Brasil, 1996, p.109-114), como se segue: 
1. Os documentos e suas condições de produção;

2. As propostas e seus fundamentos teóricos: o discurso e a prática;

3. Estrutura, organização e funcionamento da educação infantil;

4. Política de valorização e profissionalização dos recursos humanos;

5. Articulação, relação entre a Educação Infantil e o Ensino Fundamental.

Os resultados que apresentaremos neste artigo fazem parte da categoria: Estrutura, organização e funcionamento da educação infantil, que foi utilizada para analisarmos as Propostas Pedagógicas, sendo a rotina o aspecto de maior relevância presente nesta categoria.

Consideramos a rotina como um aspecto essencial para a organização do cotidiano das instituições, na prática pedagógica das instituições sempre está presente uma rotina ela é uma forma de organizar o cotidiano, e muitas vezes por estar tão presente acaba por não ser discutida pelos profissionais, fazendo-se muitas vezes pelo senso comum. Desta maneira optamos por analisar e discutir prioritariamente como são organizadas as rotinas e em quais princípios se fundamentam, de modo a contribuir com a superação de práticas homogeneizadoras que não consideram a criança sujeito do seu próprio conhecimento e produtor de cultura.

\section{RESULTADOS}

As observações realizadas têm como meta confrontar o cotidiano das práticas educacionais com o proposto em cada Plano Diretor das Instituições Infantis citadas. Como já exposto anteriormente, servirão de suporte teórico, literatura pertinente à temática estudada, os projetos pedagógicos denominados pela secretaria da educação como propostas pedagógicas/curriculares e os documentos legais que organizam e definem princípios norteadores da ação e do trabalho docente nas instituições que cuidam e educam a criança de 0 a 5 anos.

Os Planos Diretores apontam as rotinas como forma de organização do trabalho na educação infantil, e apresentam de um modo geral, os momentos que devem conter uma rotina de educação infantil, sendo adaptada conforme as necessidades das crianças, sendo eles:

Acolhida e despedida

Rodas de conversas, historias, músicas, etc

Planejamento e avaliação

Alimentação: café da manhã/ tarde, almoço / jantar, etc

Higiene: lavar as mãos, escovar os dentes, tomar o banho, etc.

Repouso

Trabalho coletivo 
Trabalho diversificado e individual

Projetos

Recreação - parque, pátio, tanque de areia, etc

Passeios.

Nas observações percebemos que estes momentos descritos nos planos são executados de forma fixa e rígida, a rotina é organizada de forma padronizada, as atividades da semana estão descritas num quadro colado na parede, que contém os horários de cada atividade e sua organização conta com pouca ou quase nenhuma participação das crianças.

Por serem bastante utilizadas na educação infantil, se tornaram algo padronizado e repetitivo. As observações indicam que é através das rotinas que está organizado todo cotidiano das instituições de educação infantil.

As Instituições de Educação Infantil precisam organizar um cotidiano de situações agradáveis, estimulantes, que desafiem o que cada criança e seu grupo de crianças já sabem sem ameaçar sua autoestima nem promover competitividade, ampliando as possibilidades infantis de cuida e ser cuidada, de se expressar, comunicar e criar, de organizar pensamentos e ideias, de conviver, brincar e trabalhar em grupo, de ter iniciativa e buscar soluções para os problemas e conflitos que se apresentam as mais diferentes idades, e thes possibilitem apropriar-se de diferentes idades, e lhes possibilitem apropriar-se de diferentes linguagens e saberes que circulam em nossa sociedade, selecionados pelo valor formativo que possuem em relação aos objetivos definidos em seu Projeto Político Pedagógico. (BRASIL, 2009, p.9).

Como aponta as Diretrizes Curriculares Nacionais para a Educação Infantil (2009) a organização do cotidiano, precisa respeitar as especificidades da infância, os objetivos do projeto pedagógico devem estar claros de forma a contribuir com o trabalho do professor.

Os Planos Diretores são norteadores das ações dos profissionais, onde estes devem avaliar constantemente seu trabalho diário, observando a coerência entre o proposto e o vivido, as instituições de educação infantil necessitam considerar a criança como sujeito único em período singular da vida, e assim, compreender sua importância no desenvolvimento integral de todas as crianças. A Política Nacional de Educação Infantil: pelo direito das crianças de zero a seis anos à educação (2006, p.17) aponta em suas diretrizes que: “As propostas pedagógicas das instituições de Educação Infantil, devem explicitar concepções, bem como diretrizes referentes a metodologia do trabalho pedagógico e ao processo de desenvolvimento/aprendizagem...".

De acordo com Barbosa (2006, p.35) “É possível afirmar que as rotinas sintetizam o projeto pedagógico das instituições e apresentam a proposta de ação educativa dos profissionais". 
Os Planos Diretores apresentam de forma resumida as rotinas das instituições, ao analisálo não podemos concluir como realmente se dá esta organização, de acordo com as Diretrizes Curriculares Nacionais para a Educação Infantil $(2009$, p.6).

Intencionalmente planejadas e permanentemente avaliadas, as práticas que estruturam o cotidiano das Instituições de Educação Infantil devem considerar a integralidade e indivisibilidade das dimensões expressivo-motora, afetiva, cognitiva, linguística, ética, estética e sociocultural das crianças, apontar as experiências de aprendizagem que se espera promover junto ás crianças e efetivar-se por meio de modalidades que assegurem as metas educacionais do projeto pedagógico.

Nas observações realizadas percebemos que as rotinas são separadas em dois grupos, rotinas para creche de 0 a 3 anos e para pré-escola de 4 a 6 anos. A rotina da creche é composta na maior parte por momentos de cuidados e satisfação das necessidades, com poucas ou quase nenhuma atividade que priorize o educar. Na pré-escola a rotina se caracteriza em atividades de socialização e regulação de comportamentos, os cuidados começam a se tornar secundários, porém não deixam de existir.

A rotina deve ser planejada de modo a abranger as diversas relações sociais entre as crianças e crianças e crianças e adultos, também devem privilegiar necessidades individuais e coletivas do grupo, necessita de planejamento, porém de forma reflexível deve procurar reconhecer as especificidades da vida infantil, envolvendo o cuidado e as atividades de ensino de aprendizagem. De acordo com o Referencial Nacional para a Educação Infantil (RCNEI, 1998):

A rotina representa, também, a estrutura sobre a qual será organizado o tempo didático,ou seja, o tempo de trabalho educativo realizado com as crianças. A rotina deve envolver os cuidados, as brincadeiras e as situações de aprendizagens orientadas. (RCNEI, 1998, p.54).

Ao organizarem a rotina de forma que considerem as especificidades das crianças, as instituições estão oferecendo a elas, a oportunidade de desfrutarem de um ambiente aconchegante, estimulante e desafiador, e de terem acesso às coisas e pessoas diferentes do que estão acostumadas no ambiente familiar, complementando; à ação dos pais e desenvolvendo assim uma parceria entre as famílias.

O educador deve refletir e reorganizar sua rotina diariamente, pois ela deve envolver atividades de desenvolvimento e satisfação das necessidades básicas. A rotina não pode ser considerada como uma camisa de força, mas sim, como uma âncora, um ponto de partida para se organizar espaços tempos e interações que sejam significativas para as crianças. De acordo com Proença (2004, p.13): 
A rotina estruturante é como uma âncora do dia-a-dia, capaz de estruturar o cotidiano por representar para a criança e para os professores uma fonte de segurança e previsão do que vai acontecer. Ela norteia, organiza e orienta o grupo no espaço escolar diminuindo a ansiedade a respeito do que é imprevisível ou desconhecido e otimizando o tempo disponível do grupo. É um exercício disciplinar a construção da rotina do grupo, que envolve prioridades, opções, adequações as necessidades e dosagem das atividades. A associação da palavra âncora ao conceito de rotina pretende representar a base sobre a qual o professor se alicerça para poder prosseguir com o trabalho pedagógico.

Os professores devem ter ciência que a rotina é um organizador do nosso dia-a-dia, e que está presente em toda prática docente, mas, desconhecem que muitas vezes por não se discutir com as crianças e construir regras em conjunto, a rotina se torna reguladora e cerceadora dos corpos das crianças e assim sendo ignora o direito da criança em participar das decisões que organizam sua vida na instituição justamente por não considerar suas especificidades. Ao não considerá-las, as instituições impedem ou dificultam a conquista da autonomia moral e intelectual da criança, ou seja, a concepção de criança como produtora e construtora do seu próprio conhecimento está sendo negligenciada.

\section{DISCUSSÃO}

Nas análises realizadas foi possível verificar a grande diferenciação que existe entre a rotina da creche e da pré-escola. A rotina da creche é composta na maior parte por momentos de cuidados e satisfação das necessidades das crianças. Na pré-escola a rotina se caracteriza em atividades de socialização e regulação de comportamentos, os cuidados já não são prioridade, porém não deixam de existir. Verificamos também que na maioria das vezes a rotina é organizada de forma mecânica com pouca ou quase nenhuma participação das crianças.

As Diretrizes Curriculares Nacionais para Educação Infantil apontam em seu artigo 4ㅇ:

As propostas pedagógicas da Educação Infantil deverão considerar que a criança, centro do planejamento curricular, é sujeito histórico e de direitos que, nas interações, relações e práticas cotidianas que vivencia, constrói sua identidade pessoal e coletiva, brinca, imagina, fantasia, deseja aprende, observa, experimenta, narra,questiona e constrói sentido sobre a natureza e sociedade produzindo cultura. (BRASIL, 2009, p.19).

Conforme afirma Barbosa (2006, p.179) "o mundo das rotinas das creches e das préescolas é um mundo de socialização que procura fazer com que crianças diferentes criem hábitos, procedimentos, gostos e desejos iguais." Contudo, podemos considerar que a organização da 
rotina sintetiza o trabalho pedagógico e traz consigo a ação do profissional e sua concepção de infância, sua organização é de extrema importância para que os profissionais possam fazer uma interação entre as necessidades físicas e cognitivas da criança.

É preciso considerar a criança como um cidadão de hoje, e não um futuro homem, considerar sua forma singular de ver e agir sobre o mundo, que constrói conhecimento a partir das relações e interações que estabelece com sua família e nas instituições de educação infantil.

Conforme afirma Francesco Tonucci(2005, p.16).

A criança não é um futuro homem, uma futura mulher ou um futuro cidadão. Ela é uma futura pessoa titular de direitos, com uma maneira própria de pensar e ver o mundo. A escola deve propor desde a Educação Infantil as experiências sobre as quais será possível fundamentar seus saberes e suas habilidades.

Portanto concluímos que ao analisarmos os Planos Diretores das seis instituições de educação infantil conseguimos identificar de modo preliminar como são organizadas as rotinas. Ao realizarmos as observações percebemos que as rotinas precisam ser refletidas e repensadas pelos profissionais que atuam com crianças de 0 a 5 anos de idade, é preciso considerar o contexto de cada instituição, as características das crianças que são atendidas, avaliar os objetivos que as instituições apontam em suas propostas pedagógicas e principalmente dar voz as crianças, que nelas são educadas e cuidadas.

Conforme afirma Barbosa (2006, p.203) "Redescrever as rotinas. Criar novas narrativas para situar o seu fazer cotidiano e poder contar e recontar seu dia-a-dia é um dos meios para aprendera rotina e dar a ela uma nova configuração, um novo significado."

\section{CONCLUSÃO}

Os resultados aqui apontados indicam a necessária ressignificação das rotinas na educação infantil, dado seu papel homogeneizador na organização do cotidiano das instituições a partir da visão adultocêntrica, no sentido de superá-las e, para tanto, estabelecer novas relações, repensar o cotidiano, prestando atenção às práticas é um dos caminhos necessários para a promoção de mudanças que contribuam com as práticas dos profissionais que atuam com a criança pequena.

\section{REFERÊNCIAS}

ANDRÉ, M. E. D. A. de. Pesquisa em educação: buscando rigor e qualidade. Caderno PESQUISA. São Paulo, n.o 113, jul. 2001. 
BARBOSA, Maria Carmem Silveira. Por Amor e por Força: Rotinas na Educação Infantil. Porto Alegre: Artmed, 2006.

BOGDAN, R.C.; BIKLEN, S. K. Investigação Qualitativa em Educação: uma introdução à teoria e aos métodos. Porto, Porto Editora, 1994.

BRASIL, Ministério da Educação e do Desporto. Secretaria de educação Fundamental. Departamento da Política de Educação Fundamental. Coordenação-Geral de Educação Infantil. Proposta pedagógica e currículo em educação infantil: um diagnóstico e a construção de uma metodologia de análise. Brasília: MEC/SEF/DPEF/COEDI, 1996.

BRASIL, Ministério da Educação. Secretaria de Educação. Referencial Curricular Nacional para Educação Infantil. Brasília: MEC/SEF, 1998. V, 1.p.54.

. Diretrizes Curriculares Nacionais para a Educação Infantil. Parecer CNE/CEB n0 20/2009.

LUDKE, M.; ANDRÉ, M. E. D. A. Pesquisa em educação: abordagens qualitativas. São Paulo: EPU, 1986.

- Ministério da Educação. Secretaria de Educação Básica. Política Nacional de Educação Infantil: pelo direito das crianças de zero a seis anos de idade à educação. Brasília: MEC/SEB, 2006.

MAZZOTTI, A. J.A; GEWANDSZNAJDER, F. O método nas ciências naturais e sociais: pesquisa quantitativa e qualitativa. 2. Ed. São Paulo, Pioneira, 1999.

PROENÇA, Maria Alice de Rezende. A rotina como âncora do cotidiano na Educação Infantil, Porto Alegre, n.4, p. 13-15, 04 abr. 2004.

TONUCCI, Francesco. Quando as crianças dizem: Agora Chega. Porto Alegre: Artmed, 2005. 